\title{
Metabolic shift in density-dependent stem cell differentiation
}

\author{
Simar J. Singh ${ }^{1}$, William Turner ${ }^{2}$, Drew E. Glaser ${ }^{2}$, Kara E. McCloskey ${ }^{2}$ and Fabian V. Filipp ${ }^{1^{*}}$ (D)
}

\begin{abstract}
Background: Vascular progenitor cells (VPCS) derived from embryonic stem cells (ESCs) are a valuable source for cell- and tissue-based therapeutic strategies. During the optimization of endothelial cell (EC) inductions from mouse ESCs using our staged and chemically-defined induction methods, we found that cell seeding density but not VEGF treatment between $10 \mathrm{ng} / \mathrm{mL}$ and $40 \mathrm{ng} / \mathrm{mL}$ was a significant variable directing ESCs into FLK $1^{+}$VPCs during stage 1 induction. Here, we examine potential contributions from cell-to-cell signaling or cellular metabolism in the production of VPCs from ESCs seeded at different cell densities.

Methods: Using 1D ${ }^{1} \mathrm{H}-\mathrm{NMR}$ spectroscopy, transcriptomic arrays, and flow cytometry, we observed that the density-dependent differentiation of ESCs into $\mathrm{FLK}^{+}$VPCS positively correlated with a shift in metabolism and cellular growth.

Results: Specifically, cell differentiation correlated with an earlier plateauing of exhaustive glycolysis, decreased lactate production, lower metabolite consumption, decreased cellular proliferation and an increase in cell size. In contrast, cells seeded at a lower density of 1,000 cells $/ \mathrm{cm}^{2}$ exhibited increased rates of glycolysis, lactate secretion, metabolite utilization, and proliferation over the same induction period. Gene expression analysis indicated that high cell seeding density correlated with up-regulation of several genes including cell adhesion molecules of the notch family (NOTCH1 and $\mathrm{NOTCH} 4)$ and cadherin family (CDH5) related to vascular development.
\end{abstract}

Conclusions: These results confirm that a distinct metabolic phenotype correlates with cell differentiation of VPCs.

Keywords: Stem cells, Differentiation, Vascular fate, Cell seeding density, Systems biology, Metabolism, NMR, Metabolomics, Fluorescence-activated cell sorting, Flow cytometry, Cell adhesion, Cell contact, Cell communication, Microenvironment, Cancer stem cells, Embryonic stem cells, Vascular progenitor cells, Endothelial cells

\section{Background}

Vascular progenitor cells (VPCs) and endothelial cells (ECs) are desirable cell sources for cellular therapeutic and tissue engineering strategies including: peripheral vascular disease $[1,2]$, severe ischemic heart disease $[3,4]$ and lining the lumens of small diameter vascular grafts in order to minimize thrombosis or arteriosclerosis $[5,6]$. In cancer, the vascular niche promotes cancer stem cells (CSCs) and is enriched with CSC-derived ECs, which promote tumor invasion and metastasis [7]. VPCs are important for maintenance of the stemness of normal

\footnotetext{
* Correspondence: filipp@ucmerced.edu

${ }^{1}$ Systems Biology and Cancer Metabolism, Program for Quantitative Systems Biology, University of California Merced, 2500 North Lake Road, Merced, CA 95343, USA

Full list of author information is available at the end of the article
}

adult stem cells, including self-renewal, undifferentiated status, and dormancy. However, it is sometimes difficult to obtain sufficient numbers of proliferating VPCs and ECs, especially from aged adults and diseased patients [6]. Alternatively, embryonic stem cells (ESCs) and induced pluripotent stem cells (iPSCs) with their unlimited capacity for self-renewal, are considered excellent cell sources in a variety of cell-based therapies. In addition to their growing therapeutic applications, these cell sources in combination with derived VPCs and ECs can also serve as representative in vitro models of vascular development.

During early stages of vascular development, signaling from vascular endothelial growth factor $(\mathrm{VEGF}=$ VEGFA, vascular endothelial growth factor 
A, GeneBank: 7422) and the VEGF receptor, FLK1 $($ FLK1 $=$ VEGFR $=$ KDR, kinase insert domain receptor, GeneBank: 3791) promotes ventral mesoderm and hematopoietic fate [8-10] leading to activation of the mitogen activated protein kinase pathway [11]. Endothelial, hematopoietic, and smooth muscle cells have been derived from outgrowths of $\mathrm{FLK}^{+}$VPCs, making this VEGF receptor a hallmark for identification of VPCs [12]. However, despite our growing understanding of the critical biochemical factors in development, the precise timing and quantitative levels of EC induction/activation for directing vascular fate from ESCs in vitro have remained confounding. This is complicated by the inherent variability in kinetic and autocrine signaling from ESC line-to-ESC line [13]. For example, the optimal time to induce the mouse D3-ESC line into $\mathrm{FLK}^{+}$VPCs has been reported to occur at day $4\left(\mathrm{FLK}^{+}=\right.$FLK1 positive $=$VEGFR expressing cells $)$ [14-16], while the optimal time for the corresponding mouse R1-ESC line has been reported at day 2 [17]. Additionally, while VEGF is the most published growth factor associated with directing EC differentiation, published treatment levels vary between $20 \mathrm{ng} / \mathrm{mL}$ and $50 \mathrm{ng} / \mathrm{mL}$ $[12,15,18]$. Matrix signaling is also an important signal in stem cell fate, but studies on this topic have also been conflicting. For example, it has been reported that collagen type-IV directs a higher percentage of ECs $[12,15,18]$. However, more recent studies show fibronectin promotes increased cell adhesion and/or proliferation, generating greater numbers of VPCs and ECs compared with collagen-type IV $[1,17]$. Moreover, increasing evidence supports a role for modified cellular metabolism in the regulation of stem cell self-renewal, specification, and plasticity in cancer and development [19-21]. Despite this growing understanding of cellular metabolism as a regulator of cell function, the role of cell seeding density in metabolic alterations supporting vascular fate is not defined.

Therefore, using our established staged differentiation methodology and chemically-defined media formulations (Fig. 1a), we examined a number of combinatorial variables (induction time, VEGF treatment, matrix signaling, and cell seeding density) for directing the generation of VPCs (stage 1). The results indicated that cell seeding density was a significant factor in the first stages of induction of ESCs into VPCs, especially in the A3-ESC cell line [22] generated by our own laboratory. Therefore, we set out to further examine the underlying mechanisms related to density-dependent differentiation in this ESC line.

\section{Methods \\ Embryonic stem cell culture}

Mouse A3-ESCs were extracted, generated, and cultured at $3,000 / \mathrm{cm}^{2}$ on inactivated mouse embryonic fibroblasts

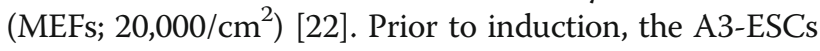
are purified from MEFs by gravity separation followed by MEF adhesion to tissue culture dishes for 1-2 hours and passaged onto $0.5 \%$ gelatin-coated plates in ESC culture media containing: Knockout Dulbecco's Modified Eagle Medium (KO-DMEM; Invitrogen), 15\% Knockout Serum Replacer (KSR; Invitrogen), 1X penicillin-streptomycin

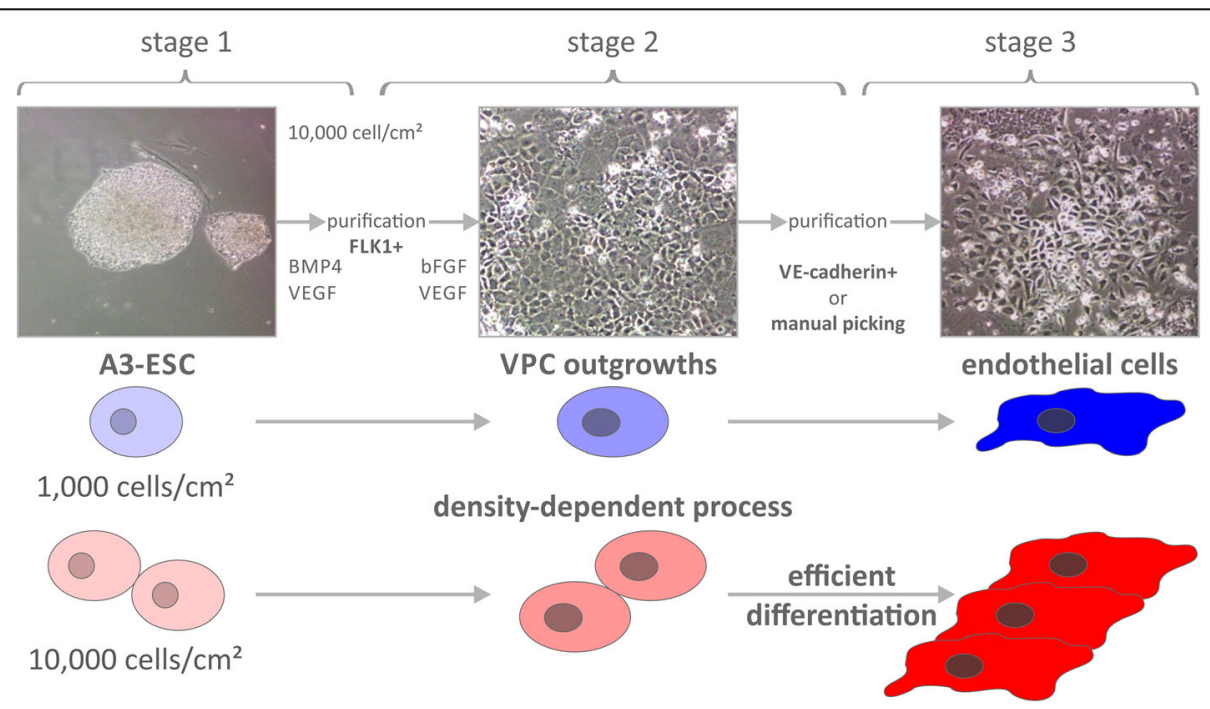

Fig. 1 Higher seeding density yields higher expression of differentiation marker FLK1 (FLK1 = VEGFR = KDR, VEGF receptor, kinase insert domain receptor). Schematic of staged differentiation of embryonic stem cells (ESCs) into vascular progenitor cells (VPCs) and endothelial cells (ECs) with representative micrographs from A3-ESCs seeded at 10,000 cells $/ \mathrm{cm}^{2}$. Stage 1 involves the culturing of ESCs on fibronectin in the presence of BMP4 (bone morphogenetic protein 4) and VEGF (vascular endothelial growth factor). At the completion of Stage 1, resulting VPCs are assayed for FLK1 receptor expression by an anti-FLK1 antibody 
(Invitrogen), 1X non-essential amino acids (Invitrogen), $2 \mathrm{mM}$ L-glutamine (Invitrogen), $0.1 \mathrm{mM}$ 2-mercaptoethanol (Calbiochem), 2000 units $/ \mathrm{mL}$ of leukemia inhibitory factor (LIF-ESGRO; Chemicon), and $10 \mathrm{ng} / \mathrm{mL}$ of bone morphogenetic protein 4 (BMP4, GeneBank: 652) (R\&D Systems). Full media changes occurred every other day and cells were passaged every $4-5$ days.

\section{Induction of $\mathrm{FLK} 1^{+}$VPCs}

A3-ESCs were harvested and plated at either 1,000, 5,000 or 10,000 cells $/ \mathrm{cm}^{2}$ in 12-well cell culture dishes, coated with $50 \mathrm{ng} / \mathrm{mL}$ fibronectin (BD Biosciences), and fed our induction media: alpha-minimal essential medium (MEM; Corning), 20\% KSR (Invitrogen), 1X penicillinstreptomycin (Invitrogen), 1X nonessential amino acids (Invitrogen), $2 \mathrm{mM}$ L-glutamine (Invitrogen), $0.05 \mathrm{mM}$ 2-mercaptoethanol (Calbiochem), and $5 \mathrm{ng} / \mathrm{mL} \mathrm{BMP4}$ (R\&D Systems), and 0 to $30 \mathrm{ng} / \mathrm{mL}$ of VEGF (R\&D Systems) without media change for 4 days. Experiments were conducted in triplicate $(N=3)$ allowing for analysis of variance. The assessment of stage 1 VPCs, which are not contact-inhibited, was quantified by the percentage of $\mathrm{FLK} 1^{+}$cells over time, previously shown to correlate with down-regulation of the pluripotent stem cell marker POU class 5 homeobox 1 (POU5F1 = OCT3/4, GeneBank: 5460) over the same time period [22].

\section{Characterization of VPCs}

Adherent cells were harvested using Cell Dissociation Buffer (Invitrogen), fixed in $4 \%$ paraformaldehyde (Tousimis), rinsed 2X with phosphate buffered saline (PBS), blocked using 0.5\% donkey serum (Fitzgerald) and $1 \%$ bovine-serum albumin (Sigma) for $1 \mathrm{~h}$ at room temperature, and stained with Alexa Fluor $647^{\circ}$-conjugated anti-FLK1 antibody (Biolegend) at 1:100 and allowed to incubate overnight at $4{ }^{\circ} \mathrm{C}$. Cells were rinsed $2 \mathrm{X}$ with PBS before being analyzed on an LSR II flow cytometer (BD Biosciences) and FloJo Software (TreeStar) at 1, 2, and 3 days post induction of differentiation. Samples were analyzed in triplicate $(N=3)$ for each data point.

\section{Exometabolome analysis}

Triplicate samples of conditioned induction media $(N=3)$ were harvested at 1,2 and 3 days post-induction and stored at $-80{ }^{\circ} \mathrm{C}$. Prior to $1 \mathrm{D}{ }^{1} \mathrm{H}-\mathrm{NMR}$ spectroscopy metabolomics analysis, supernatants were extracted using 1:1 cold methanol (BDH 67-56-1) and chloroform (Amresco 0757) mixture [7]. The extracts were cleared by centrifugation at $14,000 \mathrm{~g}$ and the aqueous phase was collected. Freeze-dried metabolite samples were resuspended in $200 \mu \mathrm{L}$ of $\mathrm{H} 20$ with $5 \% \mathrm{D} 2 \mathrm{O}$ spiked with 0.75\% 3-(trimethylsilyl)propanoic-2,2,3,3-d4 acid (TSP) (Sigma 293040) to a final concentration of $2.409 \mathrm{mM}$ into $3 \mathrm{~mm}$ NMR tubes (Norrell C-S-3-HT-7). Spectra were recorded using 1D ${ }^{1} \mathrm{H}$ excitation sculpting at 512 scans, $\mathrm{d} 1=1 \mathrm{~s}, 1 \mathrm{H}$ pulse $11.0 \mu \mathrm{s}$, power level of shaped pulse $25.55 \mathrm{db}$ and an experimental time of $10 \mathrm{~min}$ at $300 \mathrm{~K}$ at an Avance II $600-\mathrm{MHz}$ spectrometer fitted with a cryogenic probe operating with TOPSPIN 2.0 (Bruker BioSpin $\mathrm{GmbH}$ ). All spectra were automatically phased, baseline corrected and referenced to TSP ( $\delta 0.00 \mathrm{ppm}$ ) using Chenomx NMR spectroscopy suite 8.1 (Chenomx Inc). Metabolite concentrations were quantified on the basis of matching chemical shifts and multiplicities to the Chenomx reference compound library. Exometabolome analysis by NMR spectroscopy provides direct comparison of absolute metabolite concentrations of analytes. Not surprisingly, the amount of metabolites excreted or taken up scales with the initial seeding density. Therefore, by normalizing each time point to the first time point post-induction, dynamic information of the system can be obtained. The total cell count prior seeding was obtained in triplicate $(N=3)$ by analyzing cells accurately using multifocal plane analysis in the TC20 automated cell counter (Biorad).

\section{Cell size and proliferation}

Cell diameter and proliferation rates were measured over the 3 days of VPC induction using an automated image-based cytometer. Cells were harvested using $0.25 \%$ trypsin-EDTA (Corning) from fibronectin coated cultures dishes at 1,2 and 3 days post induction of differentiation, stained with trypan blue, and pipetted into disposable counting chambers for counting and image analysis. Cell diameter measurements of live differentiating ESCs were obtained in the TC20 automated cell counter (Biorad). Multi-planar brightfield digital images were automatically collected, quantified, and assessed for cell number and diameter. Cell proliferation rates were calculated and densities validated from the live cells per dish $(N=6)$ over the 3 days of VPC induction.

\section{Differential gene expression}

Total RNA was extracted from undifferentiated ESCs as well as from cells 3 days post induction of differentiation using TRIzol (Sigma T9424). At least three biological replicates of RNA samples were analyzed per condition. The concentration of RNA was determined using a Nanodrop spectrophotometer (Thermo Scientific). Two micrograms of RNA was processed with the $\mathrm{RT}^{2}$ profiler array PAMM-146Z (Qiagen SABiosciences) and used to synthesize cDNA using the $\mathrm{RT}^{2}$ SYBR green master mix (Qiagen SABiosciences) in a 7300 real-time (RT) quantitative polymerase chain reaction (QPCR) System (Applied Biosystems). Gene expression profiles were analyzed using the $\triangle \triangle C T$ method. RT QPCR threshold cycle (CT) values were normalized using five different 
housekeeping genes (HKG), ACTB, actin beta, GeneBank: 60, B2M, beta-2-microglobulin, GeneBank: 567, GAPDH, glyceraldehyde-3-phosphate dehydrogenase, GeneBank: 2597, GUSB, glucuronidase beta GeneBank: 2990, and HSP90AB1, heat shock protein $90 \mathrm{kDa}$ alpha family class B member 1, GeneBank: 3326. The difference threshold cycle value $(\Delta C \mathrm{C})$ of any gene of interest (GOI) to the average housekeeping value was calculated using the formula $\Delta \mathrm{CT}(\mathrm{GOI})=\mathrm{CT}(\mathrm{GOI})-\operatorname{AVERAGE}(\mathrm{CT}(\mathrm{HKG}))$ for ESCs, differentiating cells at seeding density of $1,000 \mathrm{cells} / \mathrm{cm}^{2}$ and 10,000 cells $/ \mathrm{cm}^{2}$. In addition, change in gene expressions of any gene of interest was monitored by calculating $\Delta \Delta \mathrm{CT}(\mathrm{GOI})=\Delta \mathrm{CT}(\mathrm{GOI}-10 \mathrm{~K})-\Delta \mathrm{CT}(\mathrm{GOI}-1 \mathrm{~K})$. $\mathrm{RT}^{2}$ gene array profiles were normalized, separated according to differential expression between the two seeding densities in univariate T-tests with a random variance model using a $p$-value cut-off below 0.05 , and ranked with LOG2 fold-change of specimen seeded at 10,000 cells $/ \mathrm{cm}^{2}$ in comparison to 1,000 cells $/ \mathrm{cm}^{2}$ considered significant.

\section{Differential protein expression analysis}

Induced VPCs originally seeded as ESCs at $1,000 \mathrm{cells} / \mathrm{cm}^{2}$ or 10,000 cells $/ \mathrm{cm}^{2}$ were harvested 3 days post induction. Cells were fixed, washed, and blocked in PBS supplemented with $2 \%$ fetal bovine serum (FBS; Corning 35-010$\mathrm{CV}$ ). Cells were incubated light-protected at $4{ }^{\circ} \mathrm{C}$ for $1 \mathrm{~h}$ with the following antibodies and staining reagents: FLK1 PerCP (Biolegend 121915), CDH2 rabbit polyclonal (Abcam ab12221), CDH5 (CD144) brilliant violet 421 (Biolegend 138013), and Fixable Viability Dye eFluor780 (eBioscience 65-0865-14). After washing, cells were incubated light protected at $4{ }^{\circ} \mathrm{C}$ for $1 \mathrm{~h}$ with FITC conjugated Donkey Anti-Rabbit IgG pre-adsorbed (Abcam ab7079). Samples were rinsed twice with PBS supplemented with $2 \%$ FBS before being analyzed on an LSR II flow cytometer (BD Biosciences) at a flow rate at least 500 events per second. 100,000 events per sample were recorded and samples were analyzed in triplicate $(N=3)$ for each data point. FloJo Software (TreeStar) was used for data analysis. Dead cells were gated out from analysis based on Viability Dye eFlour780 reactivity. $\mathrm{FLK}^{+}$cells were then analyzed for FITC $(\mathrm{CDH} 2)$ and Brilliant Violet 421 (CDH5) fluorescence and the percentage of $\mathrm{Flk} 1^{+} / \mathrm{CDH} 2^{+} \mathrm{CDH} 5^{+}$cells were compared between low density and high density groups.

\section{Results}

\section{Characterization of differentiated FLK1 ${ }^{+}$VPCs}

Induction of mouse A3-ESCs [22] into VPCs was examined over a range of seeding densities, VEGF treatment levels, and time (Fig. 2a). The greatest number of FLK $1^{+}$ cells was generated on day 3 , with a reduction at day 4 . Although the VEGF treatment levels led to variable results, the greatest number of FLK1 ${ }^{+}$VPCs was consistently and statistically significant in cultures seeded at the highest seeding density (Fig. 2a-b) while cells initially seeded at 1,000 cells $/ \mathrm{cm}^{2}$ generated significantly fewer FLK $1^{+}$cells. Bright field microscopy revealed that after three days, the 10,000 cells $/ \mathrm{cm}^{2}$ seeding density remained subconfluent (Fig. 2c).

\section{Metabolic shift during density-dependent differentiation}

To identify density-dependent changes in cellular metabolism during differentiation, we measured metabolite abundance within conditioned media using $1 \mathrm{D}{ }^{1} \mathrm{H}-\mathrm{NMR}$ spectroscopy. This exometabolome analysis provides insights into metabolite utilization and secretion. A reduction in metabolite abundance is consistent with cellular uptake from our chemically defined induction media, whereas an increase in abundance correlates with active production and extracellular secretion. Of the metabolites in the differentiation media profiled, only lactate exhibited an increase in abundance. Cells seeded at a density of 10,000 cells $/ \mathrm{cm}^{2}$ displayed a rapid increase in lactate production between days 1 and 2, which then slowed between days 2 and 3 (Fig. 3a-b). Conversely, cells grown at a density of 1,000 cells $/ \mathrm{cm}^{2}$ produce, on a per cell basis, comparatively more lactate, and exhibit a significant increase in lactate abundance between days 1 and 3 (9.0 vs 3.8; $p$-value $<0.001)$ (Fig. 3a-b). The same trend is seen in metabolite utilization. Cells grown at a density of 10,000 cells $/ \mathrm{cm}^{2}$ exhibit higher rates of metabolite utilization between day 1 and day 2 , and much lower utilization between days 2 and 3 (Fig. 3c-d). In contrast, cells seeded at lower density increase their metabolite uptake over time, exhibiting their highest levels of utilization between days 2 and 3 (Fig. 3c-d).

\section{Differentiation correlates with increased cell size and reduced proliferation}

To determine whether the observed shift in metabolite utilization coincides with a change in cellular proliferation, we measured the number of live cells present for both seeding densities following induction of differentiation. Cells induced at a density of 10,000 cells $/ \mathrm{cm}^{2}$ have a higher proliferation rate between day 1 and day 2 (3.32 vs. 2.07; $p$-value $<0.001)$ and a lower proliferation rate between day 2 and day 3 (2.01 vs. 3.73; $p$-value $<0.001)$ (Fig. 4a). In contrast, cells grown at low density continue to increase their proliferation rate over the 3 days of induction. Notably, while VPCs are not contact-inhibited, cell cultures at all seeding densities remain subconfluent after 3 days of culture (Fig. 1D) and continue to proliferate. A3-ESCs seeded at the highest density contained fewer cells of a small diameter representative of ESC size three days post induction compared with cells seeded at lower density $(5-6 \mu \mathrm{m}, 26 \%$ vs $36 \%$; $p$-value $<0.001$ ). Additionally, proportionately more cells of larger 

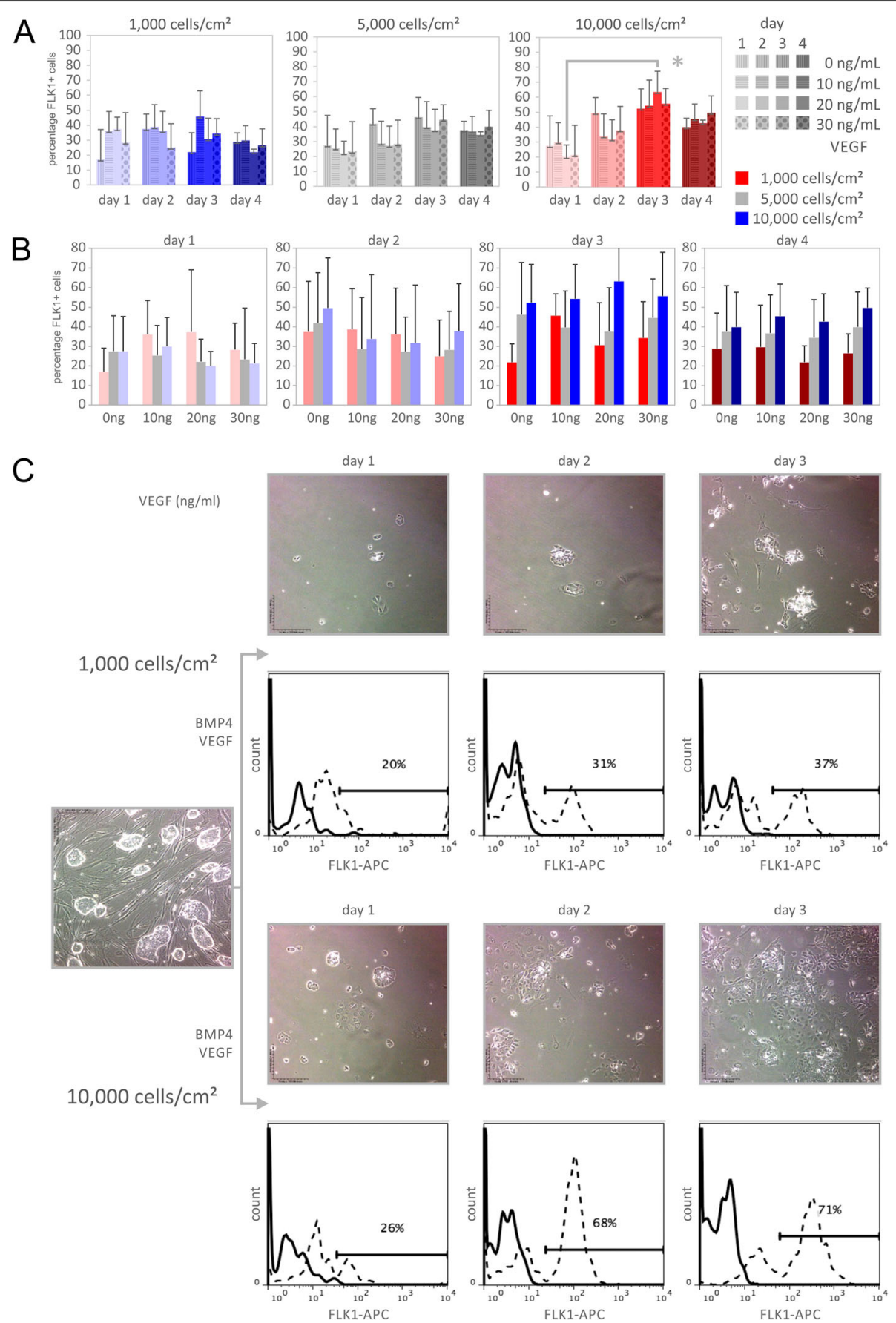

Fig. 2 Higher seeding density yields higher expression of differentiation marker FLK1 (FLK1 = VEGFR = KDR, kinase insert domain receptor). The effect of (a) seeding density, (b) vascular endothelial growth factor (VEGF) concentration, and induction time on the percentage of FLK1 ${ }^{+}$vascular progenitor cells (VPCs) generated from embryonic stem cells (ESCs). An induction time of three days combined with a seeding density of 10,000 cells/cm² resulted in high percentages of FLK $1^{+}$cells regardless of VEGF concentration. $\mathbf{c}$ Phase contrast images and flow cytometic cell scanning histograms of FLK1 expression of ESCs induced on $50 \mathrm{ng} / \mathrm{mL}$ fibronectin with $20 \mathrm{ng} / \mathrm{mL}$ VEGF treatment. Upper panel shows time course following seeding densities of 1,000 cells $/ \mathrm{cm}^{2}$. Lower panel shows time course following seeding densities of 10,000 cells $/ \mathrm{cm}^{2}$. By day 3 post induction, the majority of cells seeded at 10,000 cells/cm ${ }^{2}$ exhibit FLK1 receptor expression. In contrast, cells initially seeded at 1,000 cells/ $\mathrm{cm}^{2}$ exhibit less FLK1 receptor expression and exhibit fewer cell clusters at day 3 

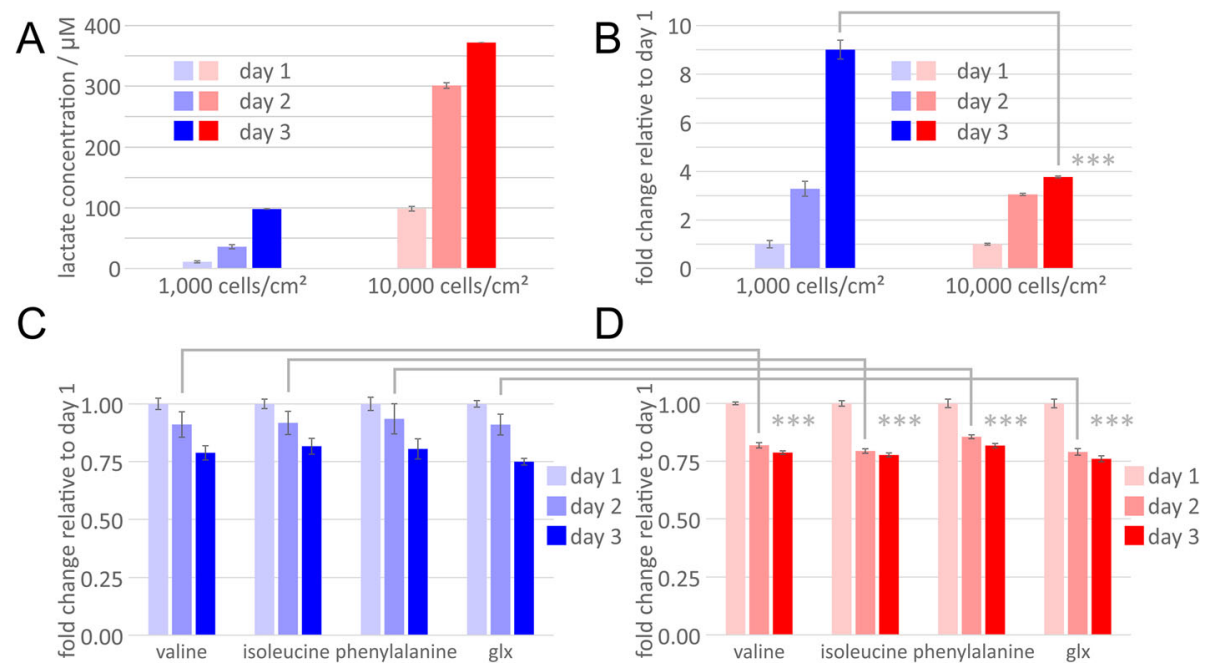

Fig. 3 Density-dependent shift of metabolic rate. 1D ${ }^{1} \mathrm{H}-\mathrm{NMR}$ spectroscopic exometabolome analysis of conditioned media from induced embryonic stem cells (ESCs) initially seeded at 1,000 cells/ $\mathrm{cm}^{2}$ (blue) and 10,000 cells/ $\mathrm{cm}^{2}$ (red). a By day 3, cells seeded at higher density reduce production of lactate whereas cells initially seeded at low density continue to increase lactate production and exhibit a significantly higher fold increase in lactate abundance between days 1 and 3 (9.0 vs 3.8; *** p-value $<0.001$ ). b Fold change of lactate production relative to day 1 . c Amino acid uptake of valine, isoleucine, phenylalanine, and glutamine/glutamate $(\mathrm{g} \mid \mathrm{x})$ significantly increases in the low density group after two days of induction (*** $p$-value $<0.001$ ). $\mathbf{d}$ Amino acid uptake plateaus between 2 and 3 days post induction in the higher density group. Fold change of amino acid uptake relative to day 1
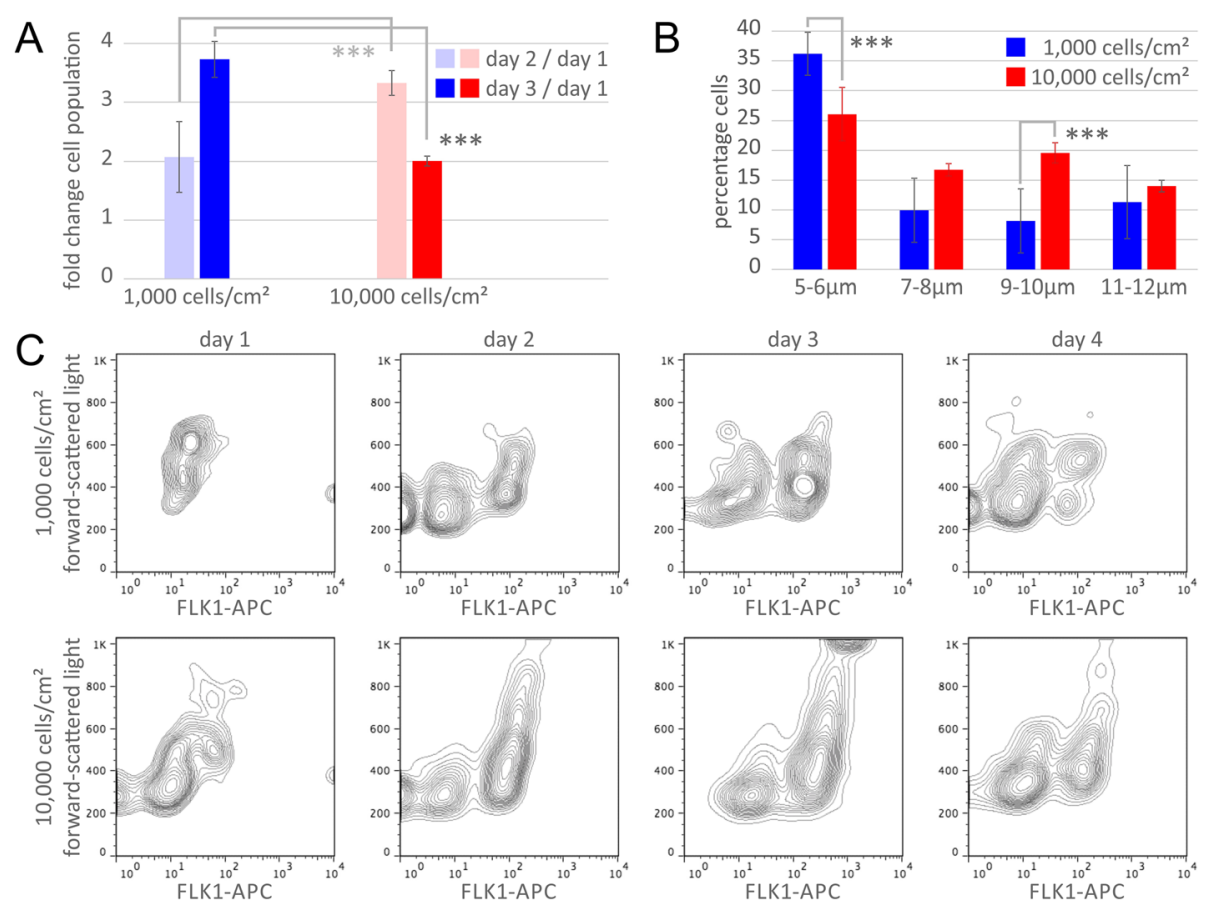

Fig. 4 Density-dependent shift of proliferation and cell diameter. a Proliferation rate significantly slows at day 3 in cells seeded at 10,000 cells/cm2 (red) but increases in cells seeded at 1,000 cells $/ \mathrm{cm}^{2}$ (blue; fold increase of $2.1 \mathrm{vs} 3.7{ }^{*}{ }^{* *} p$-value $<0.001$ ). b Higher density cells have a greater percentage of cells with large diameter $(9-10 \mu \mathrm{m}, 19.6 \%$ vs $8.2 \%$; *** $p$-value < 0.001$)$ and fewer small diameter cells $(5-6 \mu \mathrm{m}, 26.1 \%$ vs $36.2 \%$; ${ }_{* * *} p$-value $\left.<0.001\right)$. c Flow cytometric cell scanning contour plot indicating $10,000 \mathrm{cell} / \mathrm{s} / \mathrm{cm}^{2}$ seeding density results in a greater proportion of cells exhibiting high forward scatter and FLK1 allophycocyanin conjugate (APC) positivity 
diameter were found in cultures seeded at a density of 10,000 cells $/ \mathrm{cm}^{2}$ compared with lower density $(9-10 \mu \mathrm{m}$, $20 \%$ vs $8 \%$; $p$-value $<0.001$ ) (Fig. 4b). The forward scatter measurements from fluorescence-activated cell sorting in flow cytometry, another indication of cell size, show that the early A3-ESCs are smaller compared with the larger differentiated FLK1 ${ }^{+}$VPCs (Fig. 4c).

\section{Differential gene expression of cell-to-cell signaling molecules during density-dependent differentiation}

In order to further investigate the density-dependent signaling directing $\mathrm{FLK} 1^{+}$VPCs, a number of cell-to-cell signaling molecules were examined using a targeted PCR array. The expression pattern of cells seeded at densities of $10,000 \mathrm{cells} / \mathrm{cm}^{2}$ or $1,000 \mathrm{cell} / \mathrm{cm}^{2}$ revealed significant differential expression with $p$-values below 0.05 and a fold change of 2.0 or higher (Fig. 5a). Gene expression pattern included significant up-regulation of NOTCH1 (GeneBank: 4851), NOTCH4 (GeneBank: 4855), CDH4, cadherin 4, retinal, R-cadherin (GeneBank: 1002), CDH5, cadherin 5, vascular endothelium, VE-cadherin (GeneBank: 1003), DSG1B, desmoglein 1 (GeneBank: 1828), DSG2, desmoglein 2 (GeneBank: 1829), PKP1, plakophilin 1 (GeneBank: 5317), CTNNA2, catenin cadherin-associated protein alpha 2 (GeneBank: 1496), WAS, Wiskott-Aldrich syndrome (GeneBank: 7454), and WASF1, WAS protein family, member 1 (GeneBank: 8936) as well as significant down-regulation of NOTCH3 (GeneBank: 4854), and PKP2, plakophilin 2 (GeneBank: 5318).

Differential protein expression of cell-to-cell signaling molecules during density-dependent differentiation Protein level differences in cell-to-cell signaling molecule expression were quantified by flow cytometry (Fig. 6).
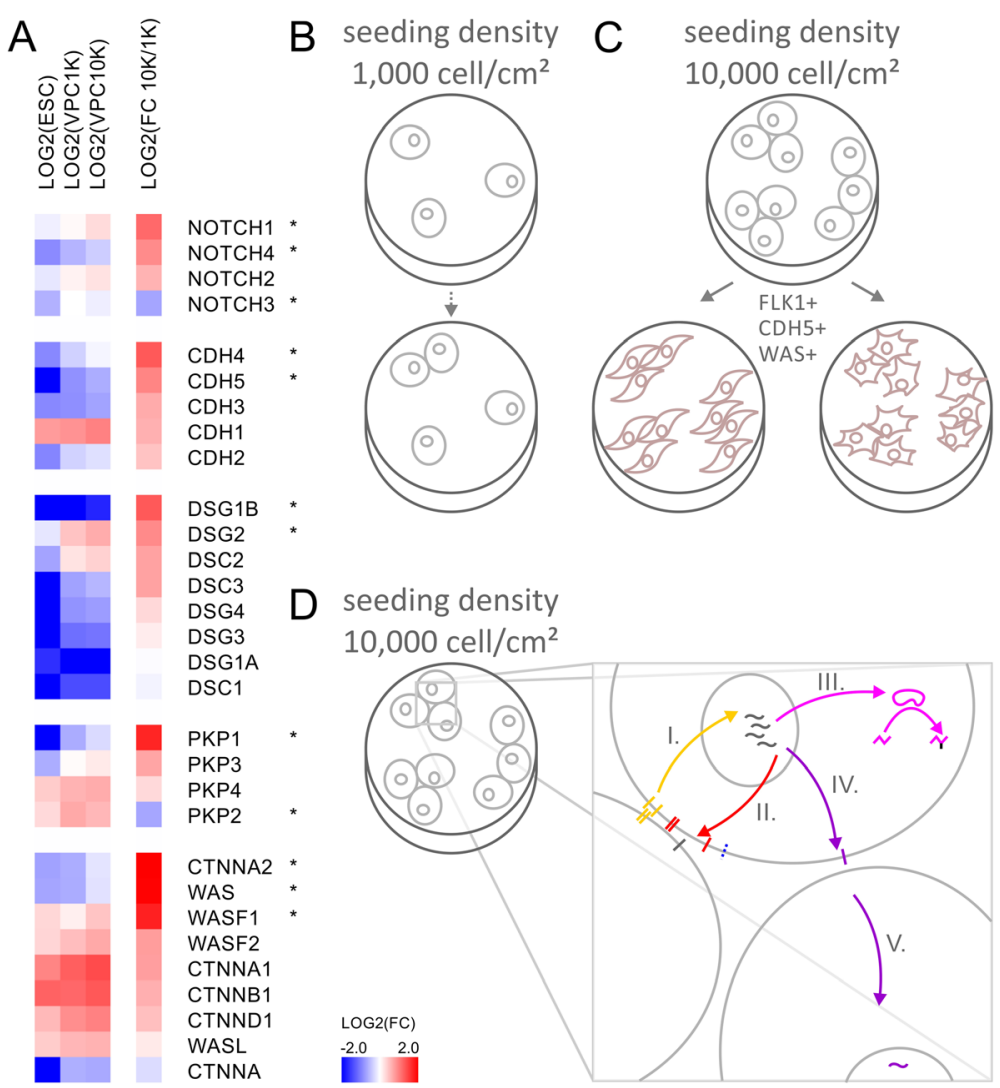

Fig. 5 Differential gene expression analysis of density-dependent differentiation identifies molecules related to cellular adhesion and vascular genesis. a Gene expression analysis of embryonic stem cells (ESCs) as well as vascular progenitor cells (VPCs) seeded at density of 1,000 vs 10,000 cells/cm². The logarithmic fold change of cells seeded at 10,000 cells/ $\mathrm{cm}^{2}$ in comparison to 1,000 cells/cm² (LOG2(FC $\left.10 \mathrm{~K} / \mathrm{K}\right)$ ) identifies density-depended processes. Gene symbols labeled with an asterisk * indicate significant differential expression with $p$-values below 0.05 . Schematic model compares: b Poor differentiation efficiency of embryonic stem cells seeded at low density of $1,000 \mathrm{cells} / \mathrm{cm}^{2}$, where isolated cells eventually die off. c Seeding of embryonic stem cells at high density of 10,000 cells $/ \mathrm{cm}^{2}$ results in expression of differentiation markers of vascular progenitor cells, which are a potent starting point for tissue engineering. $\mathbf{d}$ Enlarged diagram of cell-cell contact shows signaling processes and positive feedback enhancing differentiation: I. Cell-cell contacts mediate signals into nucleus. II. Transcriptional changes create positive feedback enforcing cell surface contacts and stimulating regulators of adherens junctions and desmosomes. III. Switch of metabolism from exponential, proliferative mode to differentiated phenotype. IV. Enforcement of new cell surface contacts. V. Propagation of differentiation state to neighboring cells 


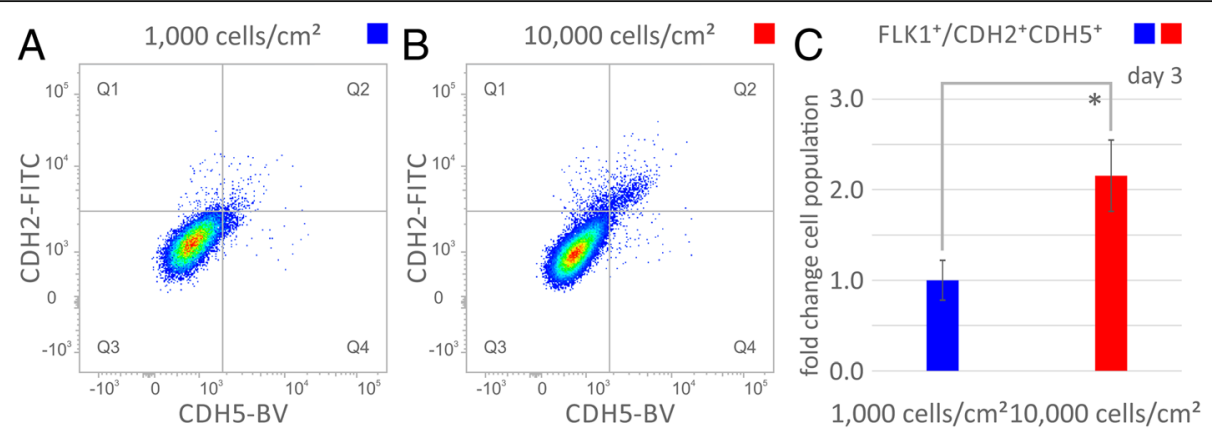

Fig. 6 Differential protein expression of cell adhesion molecules during density-dependent differentiation identifies molecules related to cellular adhesion and formation of vascularization. Protein expression analysis of induced vascular progenitor cells (VPCs) derived from embryonic stem

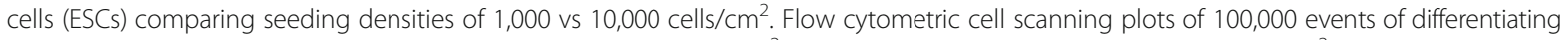
$\mathrm{FLK} 1^{+}$embryonic stem cells (a) seeded at low density of $1,000 \mathrm{cells} / \mathrm{cm}^{2}$ and (b) seeded at high density of $10,000 \mathrm{celll} / \mathrm{cm}^{2}$. The FLK1 ${ }^{+}$cells were gated in quadrant 1 (Q1) for $\mathrm{FLK}^{+} / \mathrm{CDH} 2^{+} \mathrm{CDH} 5^{-}$, in quadrant 2 (Q2) for $\mathrm{FLK}^{+} / \mathrm{CDH}^{+} \mathrm{CDH}^{+}$, in quadrant 3 (Q3) for $\mathrm{FLK} 1^{+} / \mathrm{CDH}^{-} \mathrm{CDH}^{-}$, and in quadrant 4 (Q4) for $\mathrm{FLK} 1^{+} / \mathrm{CDH} 2^{-} \mathrm{CDH}^{+}$. Markers were quantified by fluorescence of FLK1 allophycocyanin conjugate (APC), CDH2 fluorescein isothiocyanate (FITC) conjugate and $\mathrm{CDH} 5$ brilliant violet (BV) conjugate. $\mathbf{c}$ Fold change of $\mathrm{FLK} 1^{+} / \mathrm{CDH} 2^{+} \mathrm{CDH} 5^{+}$gated in $\mathrm{Q} 2$ with significant differential expression of cells derived from seeding at densities of 1,000 vs 10,000 cells $/ \mathrm{cm}^{2}$ indicated by asterisk * with $p$-value below 0.05

Induced VPCs originally seeded at $1,000 \mathrm{cell} / \mathrm{cm}^{2}$ or 10,000 cells $/ \mathrm{cm}^{2}$ were stained and analyzed for FLK1, CDH2 (cadherin 2, neuronal, N-cadherin, GeneBank: 1000) and CDH5 expression. Importantly, the cell adhesion molecule CDH5, VE-cadherin, is indicative of vascular endothelial differentiation. The percentage of cells staining positive for $\mathrm{FLK} 1, \mathrm{CDH} 2$, and $\mathrm{CDH} 5, \mathrm{FLK}^{+} / \mathrm{CDH} 2^{+} \mathrm{CDH}^{+}$, quadrant 2, (Fig. 6a-b) was higher for cells originally seeded at 10,000 cells $/ \mathrm{cm}^{2}$ than those seeded at 1,000 cells $/ \mathrm{cm} 2$ $(1.51 \%$ vs $0.70 \%, p<0.01)$ (Fig. $6 \mathrm{c}$ ).

\section{Discussion}

The generation of FLK1 ${ }^{+}$VPCs from ESCs peaks on day 3 , followed by a reduction in FLK1 ${ }^{+}$numbers (Fig. 2ab) within the range of reported days (2-5) during mesoderm induction from ESCs $[15,17,22-25]$. The other significant variable in the efficient induction of VPCs was a high cell seeding density (Fig. 2a-b), while VEGF treatment level was not significant. The higher density and robustly differentiating VPC cultures also correlated with reduced proliferation rates and greater cell diameters, both indicative of differentiation (Fig. 4). Although these cells are not contact inhibited nor were they confluent cultures, hypoxia is known to drive mesoderm commitment $[26,27]$ and endothelial fate [19] from ESCs. To determine whether hypoxia could drive ESC differentiation, we calculated the molar fraction of oxygen at the cell surface of our high density cell dishes cultures. Using our experimental cell proliferation rates, estimated oxygen solubility in saline solution, and oxygen consumption rates reported for both ESCs $=27.5 \times 10^{-18} \quad[28]$ and ECs $=50 \times 10^{-18} \mathrm{~mol} / \mathrm{cell} / \mathrm{s}$ [20], it was determined that, although oxygen would be reduced at higher cell seeding densities, none of the conditions would generate a hypoxic environment (defined as $1-3 \%$ oxygen).
Interestingly, VEGF treatment was not a determining or statistically significant variable in directing VPC fate. A large body of data implicates VEGF signaling in mesoderm and endothelial cell fate and that the FLK1/VEGF receptor is one of the key markers defining the angioblast cell $[12,14,29,30]$. However, since BMP4 signaling can also activate the VEGF/VEGFR signaling [31, 32], it is sufficient in the inductions shown. Moreover, the two distinct VEGF binding domains in the fibronectin matrix [33] may stabilize and protect autocrine VEGF production from degradation [33], as well as, aid in cell presentation. The presumptive requirement of VEGF treatment in chemicallydefined media for EC fate has been most rigorously examined using single cells cultured in collagen-type IV coated 96-well plates [12, 30, 34]. Without fibronectin matrix to sequester and protect the VEGF generated by the cells, one might expect that VEGF treatment would be required in these cultures. However, our results suggest that the utilization of fibronectin matrix mitigates the need for VEGF supplementation in VPC induction cultures.

Differential gene expression array analysis identified a number of cell-to-cell signaling molecules that were upregulated in the higher density cultures containing more VPCs. Differential expression of cell surface receptors, desmosome, catenins, and cytoskeleton regulators could be required for, or facilitate, the density-dependent differentiation of ESCs (Fig. 5b-d). Vascular cells take advantage of many different cell adhesion contacts demonstrated by the global up-regulation of cadherins, desmosomal and desmoglein components. Since cell surface molecules have the ability to communicate extracellular changes into the cytosol, such as contact formation with neighboring cells, the gene expression data suggests a positive feedback reinforcing cellular contacts (Fig. 5d). Initial cell-cell contacts mediate signals into the nucleus, 
where transcriptional changes create positive feedback promoting and strengthening cell surface contacts and stimulating regulators of adherens junctions and desmosomes. Positive feedback circuits have the ability to create threshold densities for successful differentiation. Once established and supported by the cell type specific cell surface contacts molecules, signals of differentiation can lead to lineage committed cell fates and organized tissue formation.

Amongst genes exhibiting the strongest change in the context of seeding density-dependent differentiation of VPCs were the cytoskeleton regulators WAS and CTNNA2. The expression pattern for both genes is unaffected in the lower density cohort but was consistently up-regulated in the higher density cohort. Wiskott-Aldrich syndrome protein (WASP) is a key regulator of endothelial cell-cell junctions and cytoskeleton dynamics and helps form and maintain the integrity and function of EC monolayers [35]. Moreover, WASP organizes actin and vascular epitheliumcadherins at EC junctions, and hence is vital for the assembly of vascular structures [35-37]. Importantly, along with FLK1 expression, WAS and CDH5 are also indicators of vascular differentiation [8]. Other studies have identified members of the E-twenty six (ETS) transcription factor family associating with FLK1 and $\mathrm{CDH} 5$ promoters in vascular epithelia to regulate vascular specification from primitive mesoderm [8-10, 38]. In murine and amphibian model organisms, plakophilins have been found localized to the nucleus of ESCs and form complexes with members of the ETS family of transcription factors to direct development related gene transcription events [39].

Similar to PKP1, CTNNA1, catenin cadherin-associated protein, alpha 1 (GeneBank: 1495) and AJAP1, adherens junctions associated protein 1 (GeneBank: 55966) expression levels are correlated with advancing tumor stage and inversely related to cell proliferation [32, 40, 41]. While CTNNA2 has been found as hub for extracellular matrix organization, loss of CTNNA1 is exhibited by multiple cancer types, and restoration of CTNNA1 expression in acute myeloid leukemia cells led to lower proliferation $[27,40]$. Additionally CTNNA1 regulates differentiation events in the developing nervous system by maintaining beta-catenin signaling [42]. It is possible that the higher levels of PKP1 and CTNNA1 seen in the 10,000 cells $/ \mathrm{cm}^{2}$ density group causes these cells to slow their proliferation in favor of differentiation and growth. The regulation of desmosomal assembly by DSG1B, DSG2, and PKP1 not only enforces cell surface adhesion contacts between ECs but also regulates the cell signaling events in the cytoplasm and nucleus. DSG2 regulates actin assembly in ECs and affects proliferation via modulation of EGFR signaling [43, 44]. PKP1 associates with eukaryotic translation initiation factor 4A1 to stimulate protein translation [45] and loss of PKP1 is linked to prostate cancer proliferation [46]. Nuclear PKP1 complexes with catenin and is found bound to single stranded DNA [47]. PKP2, which is more abundant in the lower density group, binds to catenin and complexes with the RNA polymerase III holoenzyme [48].

The cadherin family uniformly responds to densitydependent differentiation [36, 37]. All cadherins assayed show up-regulation in the higher density cohort. CDH4 shows the highest density-dependent fold-change of the cadherin family. In addition to significant density-dependent up-regulation, vascular endothelial $\mathrm{CDH} 5$ is also significantly different between undifferentiated and induced ESCs. Of the desmosomal, desmocollin, and desmoglein components, DSG1B, DSG2, and PKP1 stand out as positive responders to density-dependent differentiation supporting formation of cell surface adhesion contacts in endothelial formation. For the majority of cell surface, cell junction and desmosomal components, a global increase in gene expression in response to densitydependent seeding is observed.

Among the differentiation and density-dependent effects on gene expression, perhaps the most profound is differential expression of the NOTCH receptor family. NOTCH signaling is a highly conserved intercellular signaling mechanism essential for proper cell fate choices during development [49]. Both $\mathrm{NOTCH} 1$ and NOTCH4 have both been implicated in vascular morphogenesis [50]. Moreover, NOTCH1 is found expressed in both endothelial and hematopoietic progenitor cells [51], while $\mathrm{NOTCH} 4$ is expressed in ECs, but not in hematopoietic progenitor cells [50]. $\mathrm{NOTCH} 3$ signaling is highest in late stage smooth muscle cell differentiation [52] and neural differentiation [53]. In the high cell density cultures, NOTCH1 and $\mathrm{NOTCH} 4$ were significantly up-regulated, while $\mathrm{NOTCH} 3$ is significantly down-regulated at induction conditions of 10,000 cells $/ \mathrm{cm}^{2}$ compared with the lower density cultures.

It is expected that differential expression of $\mathrm{NOTCH}$ components within ESCs seeded at higher density is, at least indirectly, responsible for the shift in metabolite utilization observed during the differentiation process. Specifically, NOTCH signaling has recently been linked to the regulation of cellular metabolism $[54,55]$, inducing glutamate uptake during the terminal differentiation of astrocytes [54]. Furthermore, NOTCH inhibition in glioma stem cells led to reductions in intracellular glutamate and glutamine, and increased lactate and threonine [55]. In the same study, it was noted that NOTCH blockade modulated the expression of multiple genes 
regulating glutamate metabolism, including glutaminase and several glutamate transporters [55]. Tight regulation of glutaminase activity and glutamate metabolism are vital features of both stem cell function and tumor survival [11, 30, 44]. Interestingly, glutamine metabolism also regulates chromatin structure and pluripotency related transcription factors, such as OCT4, and therefore may play a pivotal role in vascular development [20]. Additional studies examining the role of cell-cell signaling components, particularly $\mathrm{NOTCH}$, in the regulation of glutaminergic and other metabolic pathways could help optimize strategies for ESC differentiation and understand $\mathrm{NOTCH}$-mediated cancer progression.

An increase in cell size correlating with stem cell differentiation is intimately coupled to loss of "stemness". Moreover, larger cells proliferate more slowly compared to smaller cells [56]. While in cancer cells, a positive feedback is used to rapidly ramp up a distinct metabolic program [57], cellular differentiation is accompanied by a switch in metabolism from an exponential proliferative mode into a differentiated phenotype. During the time course of differentiation, ESCs start out as small, rapidly dividing cells, but rapidly shift away from exhaustive glycolysis and high metabolite consumption to a reduced metabolic demand per cell. This observed switch in metabolism also supports the changing demands of larger, more differentiated VPCs. Our data shows that the gene expression program of these differentiating ESCs also dynamically responds to the culture conditions at higher cellular density, and actively reinforces cell surface signaling components leading to up-regulation of genes associated with VPC fate. This strengthening of cellular communication may help regulate the concurrent switch of metabolism from an exponential, proliferative mode to a differentiated, growth permissive phenotype.

\section{Conclusions}

In summary, we have identified a density-dependent metabolic shift correlating with increased differentiation of VPCs from ESCs. This density-dependent differentiation model is associated with reduced cellular metabolism, highlighted by a decrease in exhaustive glycolysis, by a decrease in proliferation, and by an increase in cell size. Concomitant is enhanced expression of cell-cell signaling components, including those known to regulate the differentiation and metabolism of stem cells via density-sensing positive feedback circuits. In the future, efficient tissue engineering approaches may take advantage of such densitydependent switches and control crosstalk between cellcell signaling and cellular metabolism.

\section{Abbreviations}

CSCs: Cancer stem cells; CT: Threshold cycle; ECs: Endothelial cells;

ESCs: Embryonic stem cells; ETS: E-twenty six; FBS: Fetal bovine serum; GOI: Gene of interest; HKG: Housekeeping genes; iPSCs: Induced pluripotent stem cells; KO-DMEM: Knockout Dulbecco's Modified Eagle Medium; KSR: Knockout serum replacer; LIF: Leukemia inhibitory factor; MEFs: Mouse embryonic fibroblasts; MEM: Minimal essential medium; PBS: Phosphate buffered saline; QPCR: Quantitative polymerase chain reaction; RT: Real-time; TSP: (trimethylsilyl)propanoic-2,2,3,3-d4 acid; VPCs: Vascular progenitor cells; WASP: Wiskott-Aldrich syndrome protein; $\triangle \mathrm{CT}$ : Difference threshold cycle value

\section{Used gene symbols}

ACTB: actin beta, GeneBank: 60; AJAP1: adherens junctions associated protein 1, GeneBank: 55966; B2M: beta-2-microglobulin, GeneBank: 567; BMP4: bone morphogenetic protein 4, GeneBank: 652; $\mathrm{CDH} 2$ : cadherin 2, type 1, neuronal, N-cadherin, GeneBank: 1000; $\mathrm{CDH} 4$ : cadherin 4, type 1, retinal, R-cadherin, GeneBank: 1002; CDH5: cadherin 5, type 2, vascular endothelium, VE-cadherin, GeneBank: 1003; CTNNA1: catenin (cadherin-associated protein), alpha 1, GeneBank: 1495; CTNNA2: catenin (cadherin-associated protein), alpha 2, GeneBank: 1496; DSG1B = DSG1: desmoglein 1, GeneBank: 1828; DSG2: desmoglein 2, GeneBank: 1829; FLK1 = VEGFR = KDR: kinase insert domain receptor, GeneBank: 3791; GAPDH: glyceraldehyde-3-phosphate dehydrogenase, GeneBank: 2597; GUSB: glucuronidase beta, GeneBank: 2990; HSP90AB1: heat shock protein 90kDa alpha class B member 1, GeneBank: 3326; NOTCH1: notch1, GeneBank: 4851; NOTCH3: notch3, GeneBank: 4854; NOTCH4: notch4, GeneBank: 4855; PKP1: plakophilin 1, GeneBank: 5317; PKP2: plakophilin 2, GeneBank: 5318; POU5F1: OCT3/4, POU class 5 homeobox 1, GeneBank: 5460; VEGFA = VEGF: vascular endothelial growth factor A, GeneBank: 7422; WAS: Wiskott-Aldrich syndrome, GeneBank: 7454; WASF1: WAS protein family, member 1, GeneBank: 8936.

\section{Funding}

F.V.F. is grateful for the support of grant CA154887 from the National Institutes of Health, National Cancer Institute. The cell differentiation studies were funded through an NSF Integrative Graduate Education and Research Traineeship Award, an National Science Foundation Science and Technology Center for the Emergent Behavior of Integrated Biological Systems Award, and California Institute for Regenerative Medicine Award. This collaborative endeavor was supported by grants from the University of California Cancer Research Coordinating Committee CRCC CRN-17-427258, University of California Academic Senate Graduate and Research Council and the Health Sciences Research Institute.

\section{Availability data and materials}

Not applicable to this article as all data generated is included in this this study.

\section{Authors' contributions \\ SJS, WT, FVF carried out cell density experiments, FVF conducted metabolomics experiments, SJS quantified metabolite levels and cell proliferation rates, DEG, SJS, FVF carried out flow cytometry analysis and image processing. FVF, KEM conceived and designed the study. FVF, SJS wrote the manuscript. All authors read and approved the final manuscript.}

\section{Competing interests}

The authors declare that they have no competing interests.

Ethics approval and consent to participate

Not applicable.

All experimental protocols were approved by the Institutional Review Board at the University of California Merced. The study was carried out as part of IRB UCM13-0025 of the University of California Merced as part of dbGap ID 5094.

\section{Publisher's Note}

Springer Nature remains neutral with regard to jurisdictional claims in published maps and institutional affiliations.

\section{Author details}

${ }^{1}$ Systems Biology and Cancer Metabolism, Program for Quantitative Systems Biology, University of California Merced, 2500 North Lake Road, Merced, CA 
95343, USA. ${ }^{2}$ Program for Biological Engineering and Small-scale Technologies, School of Engineering, University of California Merced, 5200 North Lake Road, Merced, CA 95343, USA.

Received: 26 October 2016 Accepted: 2 May 2017

Published online: 20 October 2017

\section{References}

1. Kalka C, Masuda H, Takahashi T, Kalka-Moll WM, Silver M, Kearney M, Li T, Isner JM, Asahara T. Transplantation of ex vivo expanded endothelial progenitor cells for therapeutic neovascularization. Proc Natl Acad Sci U S A. 2000;97:3422-7.

2. Soker S, Machado M, Atala A. Systems for therapeutic angiogenesis in tissue engineering. World J Urol. 2000;18:10-8.

3. Kawamoto A, Gwon HC, Iwaguro H, Yamaguchi Jl, Uchida S, Masuda H, Silver M, Ma H, Kearney M, Isner JM, Asahara T. Therapeutic potential of ex vivo expanded endothelial progenitor cells for myocardial ischemia. Circulation. 2001;103:634-7.

4. Kocher AA, Schuster MD, Szabolcs MJ, Takuma S, Burkhoff D, Wang J, Homma S, Edwards NM, Itescu S. Neovascularization of ischemic myocardium by human bone-marrow-derived angioblasts prevents cardiomyocyte apoptosis, reduces remodeling and improves cardiac function. Nat Med. 2001;7:430-6.

5. Kaushal S, Amiel GE, Guleserian KJ, Shapira OM, Perry T, Sutherland FW Rabkin E, Moran AM, Schoen FJ, Atala A, et al. Functional small-diameter neovessels created using endothelial progenitor cells expanded ex vivo. Nat Med. 2001;7:1035-40.

6. Griese DP, Ehsan A, Melo LG, Kong D, Zhang L, Mann MJ, Pratt RE, Mulligan RC, Dzau VJ. Isolation and transplantation of autologous circulating endothelia cells into denuded vessels and prosthetic grafts: implications for cell-based vascular therapy. Circulation. 2003;108:2710-5.

7. Ping YF, Zhang X, Bian XW. Cancer stem cells and their vascular niche: Do they benefit from each other? Cancer Lett. 2016;380:561-7.

8. Kohler EE, Wary KK, Li F, Chatterjee I, Urao N, Toth PT, Ushio-Fukai M, Rehman J, Park C, Malik AB. Flk1+ and VE-cadherin + endothelial cells derived from iPSCs recapitulates vascular development during differentiation and display similar angiogenic potential as ESC-derived cells. PLOS ONE. 2013;8:e85549.

9. Lee D, Park C, Lee H, Lugus JJ, Kim SH, Arentson E, Chung YS, Gomez G, Kyba M, Lin S, et al. ER71 acts downstream of BMP, Notch, and Wnt signaling in blood and vessel progenitor specification. Cell Stem Cell. 2008;2:497-507.

10. Kataoka H, Hayashi M, Nakagawa R, Tanaka Y, Izumi N, Nishikawa S, Jakt ML, Tarui H. Etv2/ER71 induces vascular mesoderm from Flk1 + PDGFRalpha + primitive mesoderm. Blood. 2011;118:6975-86.

11. Teng L, Lei HM, Sun F, An SM, Tang YB, Meng S, Wang CH, Shen Y, Chen HZ Zhu L. Autocrine glutamatergic transmission for the regulation of embryonal carcinoma stem cells. Oncotarget. 2016;7:49552-64.

12. Yamashita J, Itoh $H$, Hirashima M, Ogawa M, Nishikawa S, Yurugi T, Naito M, Nakao K. Flk1-positive cells derived from embryonic stem cells serve as vascular progenitors. Nature. 2000;408:92-6.

13. Kattman SJ, Witty AD, Gagliardi M, Dubois NC, Niapour M, Hotta A, Ellis J, Keller G. Stage-specific optimization of activin/nodal and BMP signaling promotes cardiac differentiation of mouse and human pluripotent stem cell lines. Cell Stem Cell. 2011;8:228-40.

14. Glaser DE, Gower RM, Lauer NE, Tam K, Blancas AA, Shih AJ, Simon SI, McCloskey KE. Functional Characterization of Embryonic Stem Cell-Derived Endothelial Cells. J Vasc Res. 2011;48:415-28.

15. McCloskey KE, Lyons I, Rao RR, Stice SL, Nerem RM. Purified and proliferating endothelial cells derived and expanded in vitro from embryonic stem cells. Endothelium. 2003:10:329-36.

16. McCloskey KE, Smith DA, Jo H, Nerem RM. Embryonic Stem Cell-Derived Endothelial Cells May Lack Complete Functional Maturation in vitro. J Vasc Res. 2006:43:411-21.

17. Blancas A, Shih, AJ, Lauer, NE, McCloskey KE. Endothelial Cells from Embryonic Stem Cells in a Chemically Defined Medium. Stem Cells Dev. 2011;20:2153-61.

18. Nishikawa SI, Nishikawa S, Hirashima M, Matsuyoshi N, Kodama H. Progressive lineage analysis by cell sorting and culture identifies FLK1 + VE-cadherin + cells at a diverging point of endothelial and hemopoietic lineages. Development. 1998;125:1747-57.
19. Sasaki M, Knobbe CB, Munger JC, Lind EF, Brenner D, Brustle A, Harris IS, Holmes R, Wakeham A, Haight J, et al. IDH1(R132H) mutation increases murine haematopoietic progenitors and alters epigenetics. Nature. 2012:488:656-9.

20. Marsboom G, Zhang GF, Pohl-Avila N, Zhang Y, Yuan Y, Kang H, Hao B, Brunengraber H, Malik AB, Rehman J. Glutamine Metabolism Regulates the Pluripotency Transcription Factor OCT4. Cell Rep. 2016;16:323-32.

21. Harjes U, Verfaillie C, Carmeliet P. Endothelial Barrier and Metabolism: New Kids on the Block Regulating Bone Marrow Vascular Niches. Dev Cell. 2016:37:210-2.

22. Glaser DE, Burns AB, Hatano R, Medrzycki M, Fan Y, McCloskey KE. Specialized mouse embryonic stem cells for studying vascular development Stem Cells Cloning. 2014;7:79-88.

23. Wu Z, Wei D, Gao W, Xu Y, Hu Z, Ma Z, Gao C, Zhu X, Li Q. TPO-Induced Metabolic Reprogramming Drives Liver Metastasis of Colorectal Cancer CD110+ Tumor-Initiating Cells. Cell Stem Cell. 2015;17:47-59.

24. Blancas AA, Lauer NE, McCloskey KE. Endothelial differentiation of embryonic stem cells. Curr Protoc Stem Cell Biol. 2008;Chapter 1:Unit 1F 5.

25. McCloskey KE, Stice SL, Nerem RM. In vitro derivation and expansion of endothelial cells from embryonic stem cells. Methods Mol Biol. 2006;330: 287-301.

26. Hamilton LK, Dufresne M, Joppe SE, Petryszyn S, Aumont A, Calon F, Barnabe-Heider F, Furtos A, Parent M, Chaurand P, Fernandes KJ. Aberrant Lipid Metabolism in the Forebrain Niche Suppresses Adult Neural Stem Cell Proliferation in an Animal Model of Alzheimer's Disease. Cell Stem Cell. 2015:17:397-411.

27. Zhang J, Ratanasirintrawoot S, Chandrasekaran S, Wu Z, Ficarro SB, Yu C, Ross CA, Cacchiarelli D, Xia Q, Seligson M, et al. LIN28 Regulates Stem Cell Metabolism and Conversion to Primed Pluripotency. Cell Stem Cell. 2016:19:66-80.

28. Drehmer DL, de Aguiar AM, Brandt AP, Petiz L, Cadena SM, Rebelatto CK, Brofman PR, Filipak Neto F, Dallagiovanna B, Abud AP. Metabolic switches during the first steps of adipogenic stem cells differentiation. Stem Cell Res. 2016:17:413-21.

29. Marcelo KL, Goldie LC, Hirschi KK. Regulation of endothelial cell differentiation and specification. Circ Res. 2013:112:1272-87.

30. Rosenberg SA, Niglio SA, Salehomoum N, Chan JL, Jeong BS, Wen Y, Li J, Fukui J, Chen S, Shin SS, Goydos JS. Targeting Glutamatergic Signaling and the PI3 Kinase Pathway to Halt Melanoma Progression. Transl Oncol. 2015;8:1-9.

31. Suzuki Y, Montagne K, Nishihara A, Watabe T, Miyazono K. BMPs promote proliferation and migration of endothelial cells via stimulation of VEGF-ANEGFR2 and angiopoietin-1/Tie2 signalling. J Biochem. 2008;143:199-206.

32. Ezaka K, Kanda M, Sugimoto H, Shimizu D, Oya H, Nomoto S, Sueoka S, Tanaka Y, Takami H, Hashimoto R, et al. Reduced Expression of Adherens Junctions Associated Protein 1 Predicts Recurrence of Hepatocellular Carcinoma After Curative Hepatectomy. Ann Surg Oncol. 2015;22 Suppl 3: 1499-507.

33. Wijelath ES, Murray J, Rahman S, Patel Y, Ishida A, Strand K, Aziz S, Cardona C, Hammond WP, Savidge GF, et al. Novel vascular endothelial growth factor binding domains of fibronectin enhance vascular endothelial growth factor biological activity. Circ Res. 2002;91:25-31.

34. Hojfeldt JW, Helin K. Regional tumour glutamine supply affects chromatin and cell identity. Nat Cell Biol. 2016:18:1027-9.

35. Mooren OL, Kim J, Li J, Cooper JA. Role of N-WASP in Endothelial Monolayer Formation and Integrity. J Biol Chem. 2015;290:18796-805.

36. Vittet D, Buchou T, Schweitzer A, Dejana E, Huber P. Targeted null-mutation in the vascular endothelial-cadherin gene impairs the organization of vascular-like structures in embryoid bodies. Proc Natl Acad Sci U S A. 1997;94:6273-8.

37. Lenard A, Ellertsdottir E, Herwig L, Krudewig A, Sauteur L, Belting HG, Affolter M. In vivo analysis reveals a highly stereotypic morphogenetic pathway of vascular anastomosis. Dev Cell. 2013;25:492-506.

38. Rasmussen TL, Kweon J, Diekmann MA, Belema-Bedada F, Song Q, Bowlin K, Shi X, Ferdous A, Li T, Kyba M, et al. ER71 directs mesodermal fate decisions during embryogenesis. Development. 2011;138:4801-12.

39. Munoz WA, Lee M, Miller RK, Ahmed Z, Ji H, Link TM, Lee GR, Kloc M, Ladbury JE, McCrea PD. Plakophilin-3 catenin associates with the ETV1/ER81 transcription factor to positively modulate gene activity. PLoS ONE. 2014;9:e86784.

40. Liu TX, Becker MW, Jelinek J, Wu WS, Deng M, Mikhalkevich N, Hsu K, Bloomfield CD, Stone RM, DeAngelo DJ, et al. Chromosome $5 q$ deletion and epigenetic suppression of the gene encoding alpha-catenin (CTNNA1) in myeloid cell transformation. Nat Med. 2007;13:78-83. 
41. Han L, Zhang KL, Zhang JX, Zeng L, Di CH, Fee BE, Rivas M, Bao ZS, Jiang T, Bigner D, et al. AJAP1 is dysregulated at an early stage of gliomagenesis and suppresses invasion through cytoskeleton reorganization. CNS Neurosci Ther. 2014:20:429-37.

42. Stocker AM, Chenn A. Focal reduction of alphaE-catenin causes premature differentiation and reduction of beta-catenin signaling during cortical development. Dev Biol. 2009;328:66-77.

43. Giusti B, Margheri F, Rossi L, Lapini I, Magi A, Serrati S, Chilla A, Laurenzana A, Magnelli L, Calorini L, et al. Desmoglein-2-integrin Beta-8 interaction regulates actin assembly in endothelial cells: deregulation in systemic sclerosis. PLOS ONE. 2013;8:e68117.

44. Ryu JM, Lee SH, Seong JK, Han HJ. Glutamine contributes to maintenance of mouse embryonic stem cell self-renewal through PKC-dependent downregulation of HDAC1 and DNMT1/3a. Cell Cycle. 2015;14:3292-305.

45. Wolf A, Krause-Gruszczynska M, Birkenmeier O, Ostareck-Lederer A, Huttelmaier S, Hatzfeld M. Plakophilin 1 stimulates translation by promoting elF4A1 activity. J Cell Biol. 2010;188:463-71.

46. Yang C, Fischer-Keso R, Schlechter T, Strobel P, Marx A, Hofmann I. Plakophilin 1-deficient cells upregulate SPOCK1: implications for prostate cancer progression. Tumour Biol. 2015;36:9567-77.

47. Sobolik-Delmaire T, Reddy R, Pashaj A, Roberts BJ, Wahl 3rd JK. Plakophilin-1 localizes to the nucleus and interacts with single-stranded DNA.J Invest Dermatol. 2010;130:2638-46.

48. Mertens C, Hofmann I, Wang Z, Teichmann M, Sepehri Chong S, Schnolzer M Franke WW. Nuclear particles containing RNA polymerase III complexes associated with the junctional plaque protein plakophilin 2. Proc Natl Acad Sci U S A. 2001;98:7795-800

49. Artavanis-Tsakonas S, Rand MD, Lake RJ. Notch signaling: cell fate control and signal integration in development. Science. 1999;284:770-6.

50. Krebs LT, Xue Y, Norton CR, Shutter JR, Maguire M, Sundberg JP, Gallahan D, Closson V, Kitajewski J, Callahan R, et al. Notch signaling is essential for vascular morphogenesis in mice. Genes Dev. 2000;14:1343-52.

51. Lardelli M, Lendahl U. Motch A and motch B-two mouse Notch homologues coexpressed in a wide variety of tissues. Exp Cell Res. 1993;204:364-72.

52. Granata A, Bernard WG, Zhao N, McCafferty J, Lilly B, Sinha S. Temporal and embryonic lineage-dependent regulation of human vascular SMC development by NOTCH3. Stem Cells Dev. 2015:24:846-56.

53. Rusanescu G, Mao J. Notch3 is necessary for neuronal differentiation and maturation in the adult spinal cord. J Cell Mol Med. 2014;18:2103-16.

54. Angulo-Rojo C, Manning-Cela R, Aguirre A, Ortega A, Lopez-Bayghen E. Involvement of the Notch pathway in terminal astrocytic differentiation: role of PKA. ASN Neuro. 2013;5:e00130.

55. Kahlert UD, Cheng M, Koch K, Marchionni L, Fan X, Raabe EH, Maciaczyk J, Glunde K, Eberhart CG. Alterations in cellular metabolome after pharmacological inhibition of Notch in glioblastoma cells. Int J Cancer. 2016;138:1246-55.

56. Dolfi SC, Chan LL, Qiu J, Tedeschi PM, Bertino JR, Hirshfield KM, Oltvai ZN, Vazquez A. The metabolic demands of cancer cells are coupled to their size and protein synthesis rates. Cancer Metab. 2013;1:20.

57. Wang Y, Huang Y, Zhao L, Li Y, Zheng J. Glutaminase 1 is essential for the differentiation, proliferation, and survival of human neural progenitor cells. Stem Cells Dev. 2014;23:2782-90.

\section{Submit your next manuscript to BioMed Central and we will help you at every step:}

- We accept pre-submission inquiries

- Our selector tool helps you to find the most relevant journal

- We provide round the clock customer support

- Convenient online submission

- Thorough peer review

- Inclusion in PubMed and all major indexing services

- Maximum visibility for your research

Submit your manuscript at www.biomedcentral.com/submit

) Biomed Central 